\title{
Le Prêteur et sa femme de Metsys : une image de la femme au travail dans la peinture proto-moderne
}

The money-changer and his wife, by Metsys: an image of a woman at work in early Renaissance painting

Marianne Cailloux

\section{OpenEdition}

Journals

Édition électronique

URL : http://journals.openedition.org/itti/683

DOI : $10.4000 /$ itti.683

Éditeur

Université de Poitiers

Référence électronique

Marianne Cailloux, « Le Prêteur et sa femme de Metsys : une image de la femme au travail dans la peinture proto-moderne », Images du travail, travail des images [En ligne], 6-7 | 2019, mis en ligne le 01 février 2019, consulté le 14 avril 2021. URL : http://journals.openedition.org/itti/683 ; DOI : https:// doi.org/10.4000/itti.683

Ce document a été généré automatiquement le 14 avril 2021

Images du travail, travail des images 


\section{Le Prêteur et sa femme de Metsys : une image de la femme au travail dans la peinture proto-moderne}

The money-changer and his wife, by Metsys: an image of a woman at work in early Renaissance painting

Marianne Cailloux

Image 1. Le Prêteur et sa femme de Quentin Metsys (1466-1530)

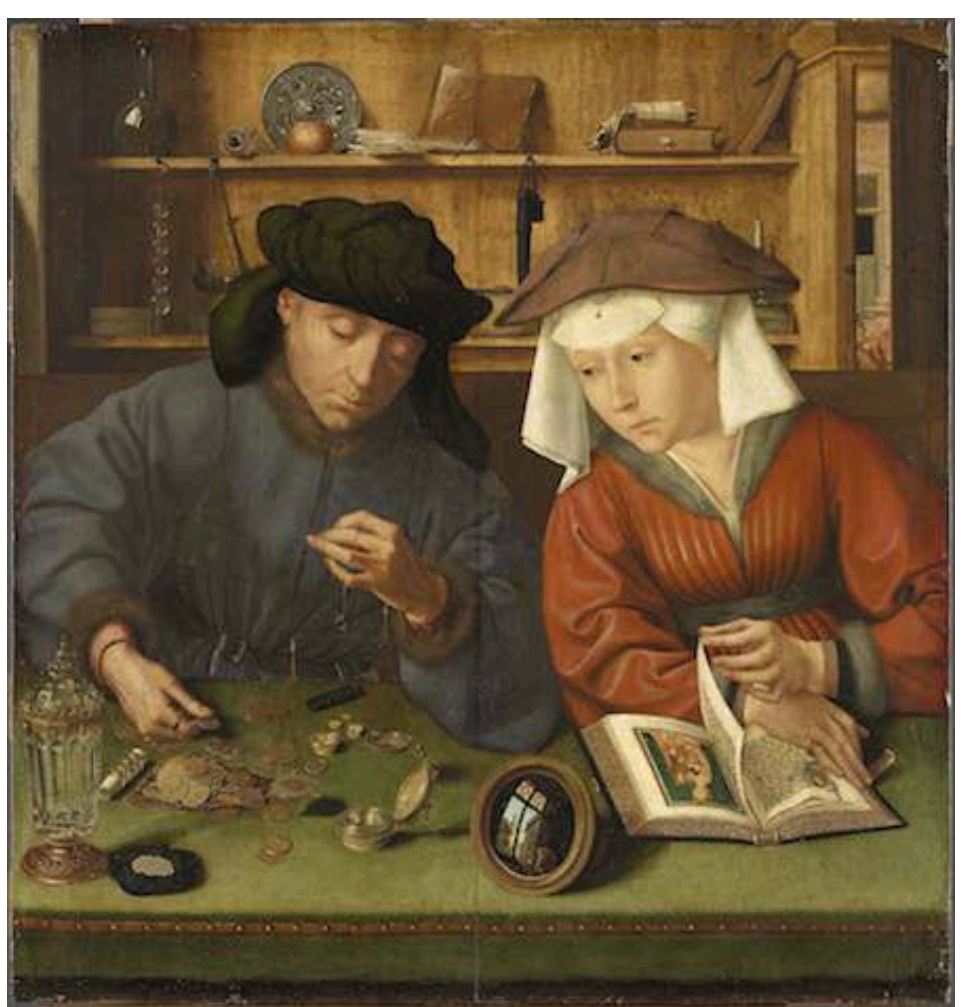


1 Dans la peinture flamande tardo-médiévale - ici un tableau de Quentin Metsys (1466-1530) - les métiers sont souvent mis en scène. À cette période, les scènes du religieux sont encore le sujet de prédilection de la peinture, privée et publique. Néanmoins, le nord de l'Europe dénote d'un goût croissant pour les représentations du quotidien, lesquelles se mélangent aux références religieuses pour gagner la faveur des récepteurs de l'ensemble des classes sociales. Le tableau montre une femme qui lit un livre d'Heures, très enluminé, au côté de son mari qui travaille dans un décor typiquement bourgeois du nord. Les objets du métier sont scrupuleusement déployés l'on peut identifier les devises de plusieurs pays étrangers, soulignant le prestige du commerce- et correspondent aux attributs du niveau social de bourgeois prospères. Posé sur la table, un miroir permet à la fois de voir le client richement vêtu et de créer une de ses mises en abyme dont les peintres de l'époque raffolent. Tout dans l'image sert la valorisation d'une réussite et d'une ascension sociales par le travail de l'argent, et la légitimation du discours bourgeois véhiculé par l'oligarchie urbaine des communes flamandes; elle est révélatrice de la perception du travail pour la période et de ses mutations à la charnière entre la fin traînante d'un Moyen Âge culturel et les bouleversements socio-économiques de l'ère moderne.

2 Si la référence mariale est indéniable - les cheveux sagement couverts, le regard chaste baissé sur ses Heures, l'anneau de foi au doigt -, les références morales surchargent l'image pour contrebalancer la négativité du métier d'argent, signalant le sérieux et la probité du couple dans un discours vertueux qui rappelle le genre de la vanité. L'aiguière, l'agneau mystique, la Vierge à l'Enfant et l'activité affichée de la femme contribuent à symboliser la caution morale de l'homme dans un métier souvent perçu comme vil. Mais ici l'épouse est distraite dans son occupation par son mari qui attire son attention sur l'objet qu'il est en train d'évaluer, de "changer» en valeur pécuniaire : le poids des métaux compte certes mais aussi la qualité de l'ouvrage, point sans doute qui explique la demande d'avis féminin, suivant la vision genrée de l'époque. Légitimée par son statut d'épouse, elle l'assiste donc, bien que cela ne soit pas son métier. Il est néanmoins possible d'interpréter l'image différemment: son mari a les yeux concentrés sur son travail, peut-être ne lui demande-t-il rien et elle est uniquement distraite. On peut penser que, comme elle est femme, elle est facilement détournée de son occupation morale par un objet précieux, illustration du genre de la vanité et de la convoitise. La double référence indique une définition morale trouble et changeante de la femme suivant l'interprétation des nombreux symboles combinés dans une image riche et nuancée.

3 Ce tableau s'inscrit dans un corpus de plusieurs peintures du même thème, où varient le nombre et le type des attributs. Le premier de la série, réalisé par Jan Van Eyck, dépeint un patron qui fait ses comptes avec son employé; dans les tableaux " suiveurs », un glissement iconographique s'opère, l'assistant cède la place à l'épouse. Celle-ci est l'employée qui ne dit pas son nom, ni payée ni reconnue, souvent sans statuts corporatifs et municipaux, elle ne fait qu'accomplir le devoir conjugal déterminé par le contrat matrimonial. Il y a là négation du rôle professionnel féminin puisque son assistanat, ponctuel ou institué, est non rémunéré, contrairement à l'apprenti. Néanmoins, sa présence dans l'image et le titre, le fait d'être mentionnée ne serait-ce qu'en tant que personne - ce qui n'est pas le cas pour d'autres tableaux similaires -, apparaît comme une forme de reconnaissance. Cette ambivalence est représentative d'une infrastructure sociale où tout est finalement contrat et labeur 
invisibilisé. La conception du labeur sous l'Ancien Régime n'a que peu à voir avec la vision actuelle du travail : l'activité professionnelle ne présente pas de claire séparation avec la vie sociale et familiale ou encore avec la sphère privée et intime. Toute la subtilité du tableau de Quentin Metsys apparaît alors, documentant la position ambigüe et complexe de la femme au travail dans la société occidentale à l'aube de la période moderne.

\section{AUTEUR}

\section{MARIANNE CAILLOUX}

Marianne Cailloux, historienne de l'image, est maîtresse de conférences en des Sciences de l'Information et de la Communication à l'université de Lille III, rattachée au laboratoire GERIICO. Ses recherches portent sur les transferts culturels, les phénomènes d'acculturation et les médiations de l'image, en pluridisciplinarité entre histoire culturelle, sciences de l'Information et de la Communication et anthropologie visuelle, principalement pour les périodes médiévale et moderne. Elle étudie par ailleurs les pionniers de la Bibliothèque et de la documentation en France. Elle a récemment publié « ÉtudiantEs à l'École des Chartes : les premières femmes en formation de conservation et de documentation (1906-1942) », dans AIDAInformazioni, rivista semestrale discienze dell'Informazione, 1-2, 2018. 